\title{
OPTIMASI EKSTRAKSI MINYAK DEDAK PADI DENGAN PELARUT ETIL ASETAT MENGGUNAKAN RESPONSE SURFACE METHODOLOGY (RSM)
}

\author{
Abdul Haris Mulyadi ${ }^{1}$, Ria Adiningsih ${ }^{2}$ \\ Program Studi Teknik Kimia, Universitas Muhammadiyah Purwokerto \\ Fakultas Teknik dan Sains, Universitas Muhammadiyah Purwokerto
}

\section{Informasi Makalah}

Dikirim, 20 November 2020

Direvisi,

Diterima, 14 April 2021

\section{Kata Kunci:}

Rice Bran Oil

Ekstraksi

Respon Surface Methodology

\section{Keyword:}

Rice Bran Oil

Extraction

Respon Surface Methodology

\begin{abstract}
INTISARI
Indonesia merupakan negara agraris dimana salah satu komoditas utamanya adalah padi, berdasarkan data BPS pada tahun 2019 telah diproduksi padi dengan jumlah total sekitar 54,6 juta ton. Proses penggilingan padi menghasilkan dedak sebanyak $10 \%$, di dalam dedak terdapat minyak dedak padi berkisar $17-22 \%$. Minyak dedak padi merupakan hasil dari ekstraksi dedak padi. Kandungan antioksidan ( $\gamma$-oryzanol, tokoferol dan tokotrienol) yang relatif tinggi dapat bermanfaat dalam berbagai bidang yaitu farmasi, kosmetik dan kesehatan. Penelitian ini bertujuan untuk mengetahui kondisi optimum ekstraksi minyak dedak dengan etil asetat sebagai pelarut melalui Respon Surface Methodology (RSM). Penelitian ini menggunakan metode ekstraksi soxhletasi dengan pelarut etil asetat, dedak padi ukuran $0,1965 \mathrm{~mm}$ sebanyak 100 gram, stabilisasi selama 15 menit pada suhu $110^{\circ} \mathrm{C}$. Untuk mendapatkan RSM penelitian dirancang mengikuti bentuk Central Composite Design (CCD) dengan dua variabel bebas, yaitu waktu ektraksi dan jumlah pelarut. Analisis data yield minyak dedak padi dilakukan dengan software Minitab Release 16. Kondisi optimum yang diperoleh untuk mengekstraksi minyak dedak padi dengan pelarut etil asetat, yaitu pada waktu ekstraksi 3,88857 jam dan jumlah pelarut 447,1205 ml dengan perolehan yield 10,8764 $\%$.
\end{abstract}

ABSTRACT
Indonesia is an agrarian country where one of its main commodities is rice.
Based on BPS data, in 2019 has been produced rice with a total amount of
about 54.6 million tons. The rice milling process produces $10 \%$ bran. In the
bran, there is rice bran oil ranging from $17-22 \%$. Rice bran oil is the result of
rice bran extraction. Its relatively high $\gamma$-oryzanol, tocopherol, and
tocotrienol) can be beneficial in various fields, namely pharmaceuticals,
cosmetics, and health. This research aims to find out the optimum conditions
of bran oil extraction with ethyl acetate as a solvent through the Surface
Methodology Response (RSM). This study used ethyl acetate solvent, rice
bran size $0.1965 \mathrm{~mm}$ as much as 100 grams, stabilization for 15 minutes at a
temperature of $110^{\circ} \mathrm{C}$. Research is designed following the form of Central
Composite Design (CCD) with two free variables, namely the time of
extraction and the number of solvents. Data analysis of yield was done with
Minitab Release 16 software. Optimum condition obtained to extract rice bran
oil with ethyl acetate solvent, at the extraction time of 3.88857 hours and the
number of solvents 447.1205 ml with a yield of $10.8764 \%$.

Korespondensi Penulis:

Abdul Haris Mulyadi 
Program Studi Teknik Kimia

Universitas Muhammadiyah Purwokerto

JL. KH Ahmad Dahlan Purwokerto, 53182

Email: harismulyadi@yahoo.com

\section{PENDAHULUAN}

Indonesia merupakan negara agraris dimana salah satu komoditas utamanya adalah padi, karena penduduk Indonesia mengkonsumsi beras sebagai makanan pokok. Dalam proses penggilingan padi menjadi beras juga menghasilkan produk samping yang hingga saat ini belum banyak di manfaatkan. Di Indonesia berdasarkan data BPS pada tahun 2019 telah diproduksi padi dengan jumlah total sekitar 54,6 juta ton. Dedak merupakan hasil samping penggilingan padi yang selama ini hanya dimanfaatkan sebagai pakan ternak. Pemanfaatan minyak dedak padi pada dedak akan meningkatkan nilai ekonomi dedak padi itu sendiri. Dedak padi sendiri tidak dapat disimpan terlalu lama. Keadaan ini disebabkan karena ketidakstabilan dedak padi selama penyimpanan. Ketidakstabilan ini disebabkan karena aktifitas enzim. Aktifitas enzim ini dapat menyebabkan kerusakan atau ketengikan. Sehingga lebih baik dimanfaatkan sebagai rice bran oil atau minyak dedak padi.

Minyak dedak dapat dikonsumsi dan mengandung vitamin, antioksidan serta nutrisi yang diperlukan tubuh manusia. Minyak dedak juga mengandung antioksidan alami tokoferol, tokotrienol dan orizanol yang bermanfaat melawan radikal bebas dalam tubuh terutama sel kanker, serta membantu menurunkan kolesterol dalam darah, kolesterol liver, serta menghambat menopause. Kadar minyak dalam dedak padi sekitar 17-22\% berat dedak. Minyak dedak padi ini biasanya disebut Rice Bran Oil (RBO). RBO dapat meningkatkan rasa dan aroma dari makanan sekaligus mengurangi penyerapan minyak selama menggoreng, memiliki antioksidan yang tinggi dan kandungan baik lainnya [1].

Penelitian ini dilakukan untuk mengetahui kondisi optimum ekstraksi minyak dedak dengan etil asetat sebagai pelarut melalui Respon Surface Methodology (RSM). Kondisi optimum yang diperoleh, dapat digunakan sebagai acuan untuk mengekstraksi minyak dedak padi menggunakan pelarut etil asetat.

\section{METODE}

Untuk mendapatkan kondisi optimum ekstraksi minyak dedak padi melalui RSM, penelitian dirancang mengikuti Central Composite Design (CCD). Titik pusat (kode 0) dalam rancangan CCD merupakan yield terbaik dari masing-masing variabel yang diperoleh dari penelitian pendahuluan sebelumnya. Titik pusat tersebut disusun sebagai level terkode penelitian yang disajikan pada tabel 1 berikut.

Tabel 1. Perlakuan Terkode

\begin{tabular}{lccccc}
\hline \multirow{2}{*}{ Perlakuan } & $\boldsymbol{5}$ Perlakuan Terkode \\
\cline { 2 - 6 } & $\mathbf{- \alpha}$ & $\mathbf{- 1}$ & $\mathbf{0}$ & $\mathbf{1}$ & $\boldsymbol{\alpha}$ \\
\hline Waktu Ekstraksi (jam) & 2,08579 & 2,5 & 3,5 & 4,5 & 4,91421 \\
Jumlah Pelarut (ml) & 258,579 & 300 & 400 & 500 & 541,421 \\
\hline
\end{tabular}

Untuk mendapatkan RSM penelitian dirancang mengikuti bentuk CCD dengan dua variabel bebas sehingga diperoleh 26 run percobaan optimasi yang disajikan pada tabel 2 berikut.

Tabel 2. Central Composite Design (CCD)

\begin{tabular}{ccccc}
\hline \multirow{2}{*}{ NNo } & \multicolumn{2}{c}{ Waktu } & Ekstraksi $\left(\mathbf{X}_{\mathbf{1}}\right)$ & \multicolumn{2}{c}{ Jumlah Pelarut $\left(\mathbf{X}_{2}\right)$} \\
\cline { 2 - 5 } & Aktual & Kode & Aktual & Kode \\
\hline 1 & 2,5 & -1 & 300 & -1 \\
2 & 4,5 & 1 & 300 & -1 \\
3 & 2,5 & -1 & 500 & 1 \\
\hline
\end{tabular}

Techno Vol. 22, No. 1, April 2021: 69-76 


\begin{tabular}{|c|c|c|c|c|}
\hline 4 & 4,5 & 1 & 500 & 1 \\
\hline 5 & 2,08579 & $-\alpha$ & 400 & 0 \\
\hline 6 & 4,91421 & $\alpha$ & 400 & 0 \\
\hline 7 & 3,5 & 0 & 258,579 & $-\alpha$ \\
\hline 8 & 3,5 & 0 & 541,421 & $\alpha$ \\
\hline 9 & 3,5 & 0 & 400 & 0 \\
\hline 10 & 3,5 & 0 & 400 & 0 \\
\hline 11 & 3,5 & 0 & 400 & 0 \\
\hline 12 & 3,5 & 0 & 400 & 0 \\
\hline 13 & 3,5 & 0 & 400 & 0 \\
\hline 14 & 2,5 & -1 & 300 & -1 \\
\hline 15 & 4,5 & 1 & 300 & -1 \\
\hline 16 & 2,5 & -1 & 500 & 1 \\
\hline 17 & 4,5 & 1 & 500 & 1 \\
\hline 18 & 2,08579 & $-\alpha$ & 400 & 0 \\
\hline 19 & 4,91421 & $\alpha$ & 400 & 0 \\
\hline 20 & 3,5 & 0 & 258,579 & $-\alpha$ \\
\hline 21 & 3,5 & 0 & 541,421 & $\alpha$ \\
\hline 22 & 3,5 & 0 & 400 & 0 \\
\hline 23 & 3,5 & 0 & 400 & 0 \\
\hline 24 & 3,5 & 0 & 400 & 0 \\
\hline 25 & 3,5 & 0 & 400 & 0 \\
\hline 26 & 3,5 & 0 & 400 & 0 \\
\hline
\end{tabular}

Dedak yang telah disiapkan, dilakukan tahap screening dengan menggunakan ayakan ukuran 60 mesh dan 100 mesh supaya ukuran dedak seragam 0,1965 mm, kemudian dikemas dalam wadah plastik bertutup. Dedak yang sudah discreening distabilisasi menggunakan oven pada suhu $110^{\circ} \mathrm{C}$ selama 15 menit. Dedak padi yang sudah kering ditimbang seberat 100 gr kemudian diletakkan pada kertas saring menunggu proses ekstraksi. Dedak padi yang telah dibungkus menggunakan kertas saring diletakkan ke dalam soxhlet extractor untuk di ekstraksi dengan jumlah pelarut etil asetat dan waktu ekstraksi sesuai dengan run percobaan optimasi. Ekstraksi berlangsung pada suhu $77-78^{\circ} \mathrm{C}$. Pemurnian produk minyak dedak padi dilakukan dengan teknik distilasi. Respon dari tiap tahap penelitian selanjutnya diolah mengunakan software Minitab Release 16.

\section{HASIL DAN PEMBAHASAN}

Hasil penelitian yang telah dilakukan yang disajikan pada tabel 3 berikut.

Tabel 3. Hasil Penelitian

\begin{tabular}{cccccc}
\hline \multirow{2}{*}{ NNo } & \multicolumn{2}{c}{ Waktu Ekstraksi $\left(\mathbf{X}_{\mathbf{1}}\right)$} & \multicolumn{2}{c}{ Jumlah Pelarut $\left(\mathbf{X}_{\mathbf{2}}\right)$} & \multirow{2}{*}{ Yield $(\%)$} \\
\cline { 2 - 5 } & Aktual & Kode & Aktual & Kode & \\
\hline 1 & 2,5 & -1 & 300 & -1 & 4,43 \\
2 & 4,5 & 1 & 300 & -1 & 8,15 \\
3 & 2,5 & -1 & 500 & 1 & 8,37 \\
4 & 4,5 & 1 & 500 & 1 & 8,83 \\
5 & 2,08579 & $-\alpha$ & 400 & 0 & 3,48 \\
6 & 4,91421 & $\alpha$ & 400 & 0 & 9,82 \\
7 & 3,5 & 0 & 258,579 & $-\alpha$ & 3,12 \\
8 & 3,5 & 0 & 541,421 & $\alpha$ & 10 \\
9 & 3,5 & 0 & 400 & 0 & 10,13 \\
10 & 3,5 & 0 & 400 & 0 & 10,15 \\
11 & 3,5 & 0 & 400 & 0 & 10,08 \\
12 & 3,5 & 0 & 400 & 0 & 10,18 \\
13 & 3,5 & 0 & 400 & 0 & 10,16 \\
14 & 2,5 & -1 & 300 & -1 & 4,52 \\
15 & 4,5 & 1 & 300 & -1 & 8,18 \\
\hline
\end{tabular}




\begin{tabular}{cccccc}
\hline 16 & 2,5 & -1 & 500 & 1 & 8,36 \\
17 & 4,5 & 1 & 500 & 1 & 8,83 \\
18 & 2,08579 & $-\alpha$ & 400 & 0 & 3,46 \\
19 & 4,91421 & $\alpha$ & 400 & 0 & 9,24 \\
20 & 3,5 & 0 & 258,579 & $-\alpha$ & 3,15 \\
21 & 3,5 & 0 & 541,421 & $\alpha$ & 10,02 \\
22 & 3,5 & 0 & 400 & 0 & 10,15 \\
23 & 3,5 & 0 & 400 & 0 & 10,2 \\
24 & 3,5 & 0 & 400 & 0 & 10,13 \\
25 & 3,5 & 0 & 400 & 0 & 10,18 \\
26 & 3,5 & 0 & 400 & 0 & 10,16 \\
\hline
\end{tabular}

\section{Analisis Pengaruh Variabel}

Pengaruh signifikansi variabel-variabel yang digunakan dapat diobservasi dari hasil pengolahan data penelitian. Analisis statistika untuk signifikansi pengaruh dari kedua variabel yaitu ukuran dedak $\left(\mathrm{X}_{1}\right)$, jumlah pelarut $\left(\mathrm{X}_{2}\right)$, dan waktu ekstraksi $\left(\mathrm{X}_{3}\right)$, serta interaksinya masing-masing tercantum pada tabel 4 berikut.

Tabel 4. Hasil Statistika Minitab 16 untuk RSM

\begin{tabular}{ccc}
\hline \multirow{2}{*}{ Parameter } & \multicolumn{2}{c}{ Hasil Analisis Statistik } \\
\cline { 2 - 3 } & Koefisien & Nilai p* \\
\hline Konstanta & 10,1520 & 0,000 \\
Waktu Ekstraksi $\left(\mathrm{X}_{1}\right)$ & 1,5906 & 0,000 \\
Jumlah Pelarut $\left(\mathrm{X}_{2}\right)$ & 1,7847 & 0,000 \\
$\mathrm{X}_{1} * \mathrm{X}_{1}$ & $-1,5954$ & 0,000 \\
$\mathrm{X}_{2} * \mathrm{X}_{2}$ & $-1,5591$ & 0,000 \\
$\mathrm{X}_{1} * \mathrm{X}_{2}$ & $-0,8062$ & 0,016 \\
$\mathrm{R}^{2}$ & $91,25 \%$ & \\
\hline Keterangan : ${ }^{*}$ Faktor signifikansi $(\mathrm{p}<0,05)$ &
\end{tabular}

Berdasarkan hasil analisis statistika tersebut, dapat diketahui bahwa peningkatan waktu ekstraksi memberikan pengaruh positif sebesar 1,5906, dan signifikan terhadap yield. Begitu pula jumlah pelarut memberikan pengaruh positif sebesar 1,7847, dan signifikan terhadap yield. Hal ini menunjukkan bahwa peningkatan yield minyak dedak padi sangat dipengaruhi oleh waktu ekstraksi dan jumlah pelarut. Interaksi antar variabel memberikan pengaruh negatif, dan signifikan terhadap yield.

Selanjutnya, model persamaan yang dapat menunjukkan hubungan variabel ekstraksi dan interaksinya terhadap persen yield minyak dedak padi diperoleh sebagai berikut:

$$
Y=10,1520+1,5906 X_{1}+1,7847 X_{2}-1,5954 X_{1}^{2}-1,5591 X_{2}^{2}-0,8062 X_{1} X_{2}
$$

\section{Analisis Plot dan Kontur Hasil Optimasi}

Dengan menggunakan grafik surface plot dan contour plot dari hasil pengolahan data menggunakan minitab 16 dapat diketahui pengaruh dari waktu ekstraksi dan jumlah pelarut terhadap yield yang dihasilkan. Pengaruh dari waktu ekstraksi dan jumlah pelarut ditampilkan dalam gambar 1 dan gambar 2 . 


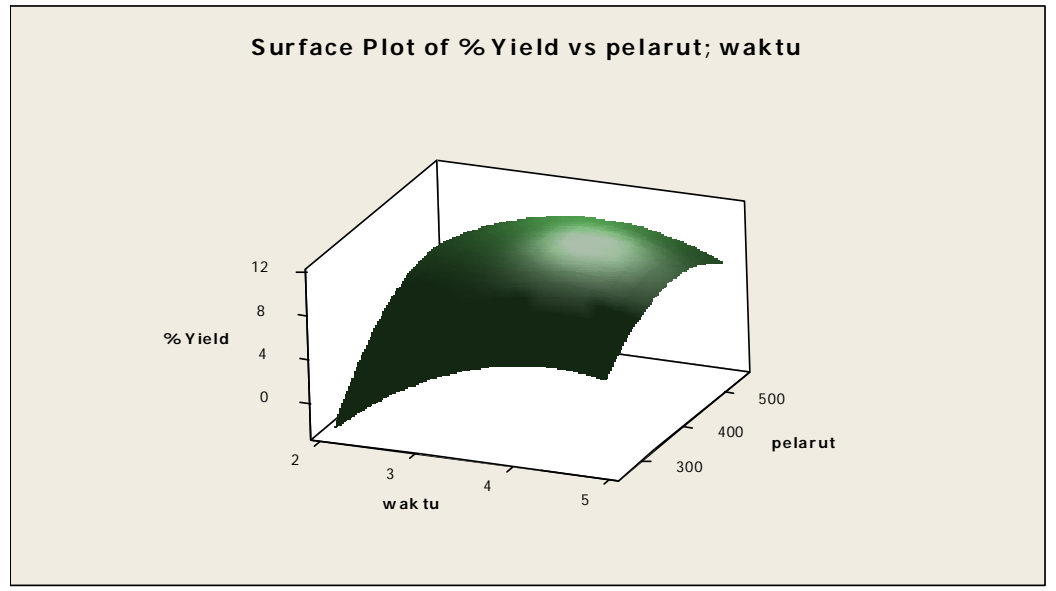

\section{Gambar 1. Surface Plot Pengaruh Waktu dan Pelarut terhadap Yield}

Gambar 1 dan gambar 2 menunjukkan bahwa yield minyak dedak padi meningkat seiring dengan peningkatan waktu ekstraksi dan jumlah pelarut hingga batasan tertentu. Batasan level yang terjadi menunjukkan bahwa peningkatan waktu ekstraksi dan jumlah pelarut tidak akan memberikan pengaruh yang signifikan terhadap yield. Permukaan kontur menunjukkan yield optimum berada pada level waktu ekstraksi $>3,5$ jam dan level jumlah pelarut $>400 \mathrm{ml}$

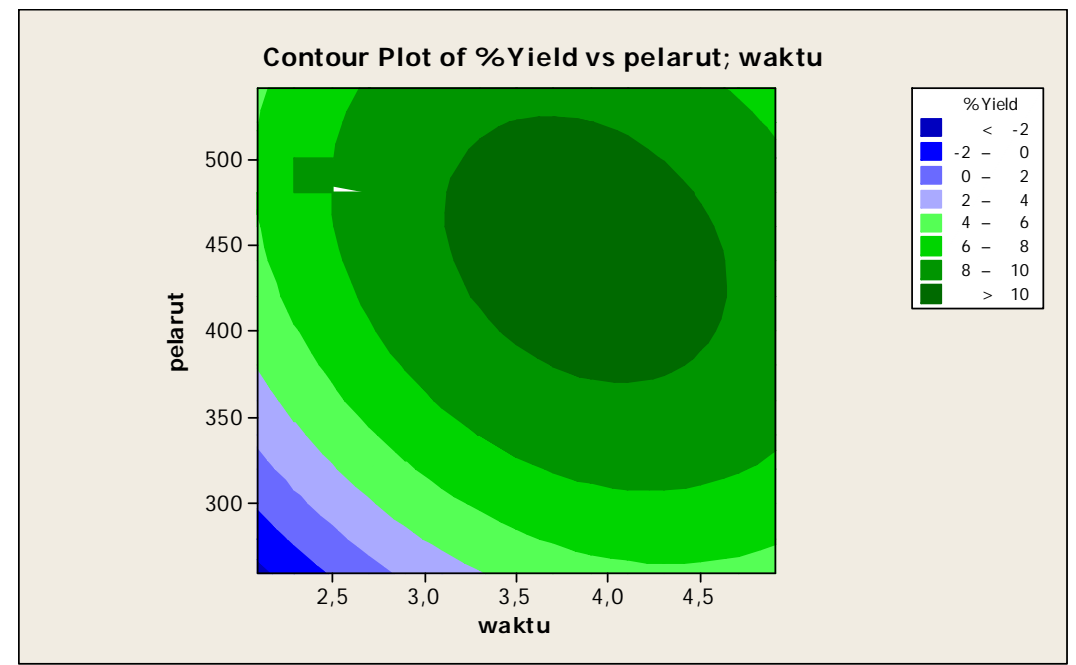

Gambar 2. Contor Plot Pengaruh Waktu dan Pelarut terhadap Yield

Yield minyak meningkat seiring dengan peningkatan waktu ekstraksi dan besarnya jumlah pelarut karena semakin banyak minyak yang larut dalam pelarut sampai tercapai kondisi kesetimbangan $[2,3]$. Kesetimbangan proses ekstraksi tercapai melalui dua tahapan yaitu tahap pertama terjadi penetrasi pelarut ke dalam sel dan melarutkan zat terlarut, dan tahapan kedua yaitu terjadinya difusi zat terlarut keluar sel melalui struktur berpori [4]. Laju transfer massa akan melambat dan berhenti pada kondisi jenuh yaitu konsentrasi zat terlarut dalam bahan dan pelarut sudah sama. Sehingga ketika waktu esktraksi dan jumlah pelarut ditingkatkan secara bersamaan dan mencapai titik jenuh, yield akan menurun.

\section{Nilai Optimum dan Titik Optimum}

Hasil optimasi mengunakan software Minitab Release 16 dapat dilihat pada gambar 3 berikut. 


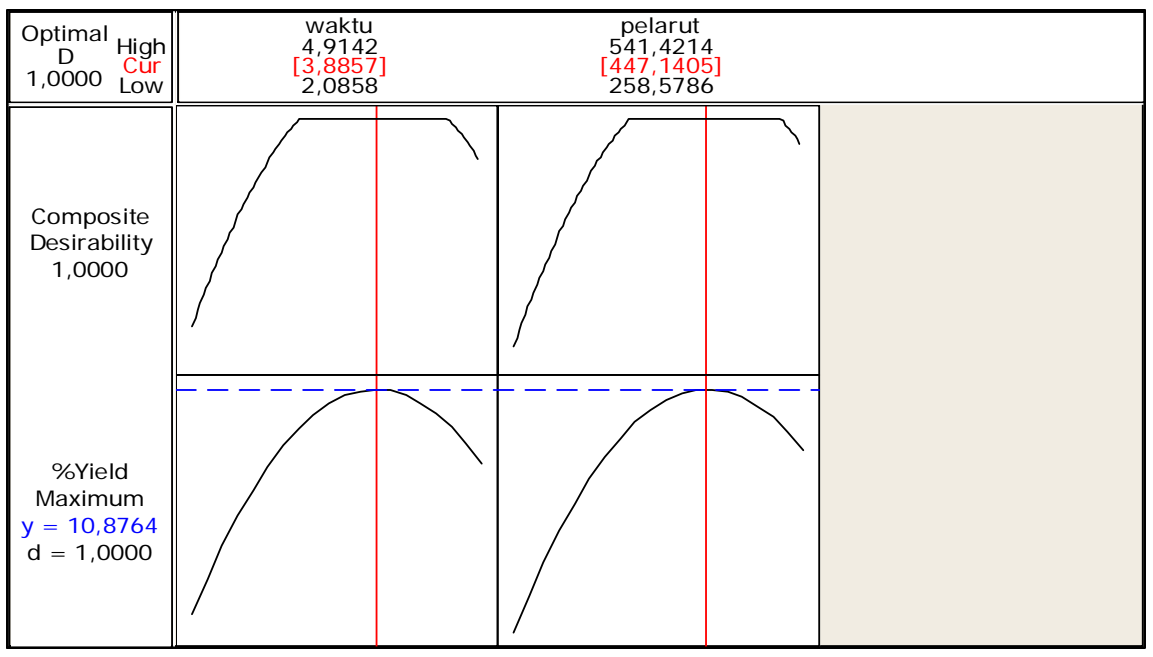

Gambar 3. Optimasi plot Yield, Waktu, Pelarut

Gambar 3. menunjukan area optimasi secara keseluruhan terhadap hasil minyak dedak padi dengan pelarut etil asetat. Nilai optimum pada penelitian ekstraksi minyak dedak padi dengan pelarut etil asetat terjadi pada waktu ekstraksi 3,8857 jam dan jumlah pelarut 447,1405 ml, dengan yield optimum yang di peroleh sebesar $10,8764 \%$

\section{Analisis Karakteristik Produk}

Hasil analisis karakteristik produk dan perbandingan produk minyak dedak padi hasil ekstraksi dengan literatur disajikan pada tabel 5 berikut.

Tabel 5. Karakteristik Produk

\begin{tabular}{lcc}
\hline \multirow{2}{*}{ Perbandingan Data } & \multicolumn{2}{c}{ Karakteristik } \\
\cline { 2 - 3 } & \%FFA & Densitas \\
\hline Minyak dedak hasil penelitian & 5,2 & 0,918 \\
Nasir [5] & $44,55-47,19$ & 0,889 \\
Suryati [6] & 2,875 & 0,901 \\
SNI & 5 & $0,91-0,92$ \\
\hline
\end{tabular}

Berdasarkan hasil penelitian yang ditampilkan dalam tabel 5, menunjukkan bahwa jumlah FFA yang diperoleh yaitu 5,2 \% yang menunjukkan asam lemak bebas sedikit melebihi SNI karena jumlah FFA diperbolehkan untuk minyak dedak padi menurut (SNI) 01- 3178- 1996 / Rev. 92 adalah 5\%. Untuk densitas pada minyak dedak padi yaitu $0,918 \mathrm{gr} / \mathrm{ml}$ yang menunjukan bahwa densitas masih berada dalam rentan SNI densitas minyak dedak padi.

\section{KESIMPULAN}

Dari hasil penelitian optimasi ektraksi minyak dedak padi dengan pelarut etil asetat menggunakan Response Surface Methodology (RSM) dapat disimpulkan bahwa, kondisi optimum yang diperoleh untuk mengekstraksi minyak dedak padi dengan pelarut etil asetat, yaitu pada waktu ekstraksi 3,88857 jam dan jumlah pelarut 447,1205 ml dengan perolehan yield 10,8764\%. 


\section{DAFTAR PUSTAKA}

[1] Ismoyo, T.A., Zahra Hanifah, Z., Ratri Ariatmi Nugrahani, R.A., 2019 , Pengaruh Waktu Sentrifugasi Terhadap Kadar y-Oryzanol Hasil Ekstraksi Rice Bran Dengan Metode Ultrasonic Bath, Seminar Nasional Sains dan Teknologi 2019, Fakultas Teknik Universitas Muhammadiyah Jakarta.

[2] Margaretta S., Handayani S.D., Indraswati N., Hindarso H., 2011, Ekstraksi senyawa phenolik Pandanus amaryllifolius Roxb sebagai antioksidan alami, Widya Teknik 10(1):21-30.

[3] Tagora B.P.S., Sirait R., Iriany, 2012, Penentuan kondisi keseimbangan unit leaching pada produksi eugenol dari daun cengkeh, Jurnal Teknik Kimia USU 1(1):10- 14.

[4] Ling-Biao G., Hui-Li P., Ke-Ke L., Hua-min L., Xue-De W., Guang-Yong Q., 2016, Process optimization and characterization of fragrant oil from red pepper (Capsicum annuum L.) seed extracted by subcritical butane extraction. Journal of The Science of Food and Agriculture 97(6): 1894-1903. doi:10.1002/jsfa.7992.

[5] Nasir,S., Fitriyanti, Hilma Kamila Nasir, H.K., 2009, Ekstraksi Dedak Padi Menjadi Minyak Mentah Dedak Padi (Crude Rice Bran Oil) Dengan Pelarut N-Hexane Dan Ethanol, Jurnal Teknik Kimia, No. 2, Vol. 16, Universitas Sriwijaya Palembang.

[6] Suryati, Ismail, A., Afriyanti, 2015, Proses Pembuatan Minyak Dedak Padi (Rice Brain Oil) Menggunakan Metode Ekstraksi, Jurnal Teknologi Kimia Unimal 4 :1 (Mei 2015) 37-45. 
